\title{
Evidence That Serum Calcium Oxalate Supersaturation Is a Consequence of Oxalate Retention in Patients with Chronic Renal Failure
}

Elaine M. Worcester, Yasushi Nakagawa, David A. Bushinsky, and Fredric L. Coe

The Renal Program, Pritzker School of Medicine, University of Chicago, Chicago, Illinois 60637

\begin{abstract}
Serum oxalate rises in uremia because of decreased renal clearance, and crystals of calcium oxalate occur in the tissues of uremic patients. Crystal formation suggests that either uremic serum is supersaturated with calcium oxalate, or local oxalate production or accumulation causes regional supersaturation. To test the first alternative, we ultrafiltered uremic serum and measured supersaturation with two different methods previously used to study supersaturation in urine. First, the relative saturation ratio (RSR), the ratio of the dissolved calcium oxalate complex to the thermodynamic calcium oxalate solubility product, was estimated for 11 uremic (before and after dialysis) and 4 normal serum samples using a computer program. Mean ultrafiltrate oxalate predialysis was $89 \pm 8 \mu \mathrm{M} /$ liter $( \pm \mathrm{SEM}), 31 \pm 4$ postdialysis, and $10 \pm 3$ in normals. Mean RSR was $1.7 \pm 0.1$ (predialysis), $0.7 \pm 0.1$ (postdialysis), and $0.2 \pm 0.1$ (normal), where values $>1$ denote supersaturation, $<1$, undersaturation. Second, the concentration product ratio (CPR), the ratio of the measured calcium oxalate concentration product before to that after incubation of the sample with calcium oxalate monohydrate crystal, was measured in seven uremic and seven normal serum ultrafiltrates. Mean oxalate was $91 \pm 11$ (uremic) and $8 \pm 3$ (normal). Mean CPR was $1.4 \pm 0.2$ (uremic) and 0.2 \pm 0.1 (normal). Predialysis, 17 of 18 uremic ultrafiltrates were supersaturated with respect to calcium oxaiate. The degree of supersaturation was correlated with ultrafiltrate oxalate (RSR, $r=0.99, n=29, P<0.001$; CPR, $r=0.75, n$ $=11, P<0.001)$. A value of ultrafiltrate oxalate of $50 \mu \mathrm{M} /$ liter separated undersaturated from supersaturated samples and occurred at a creatinine of $\sim 9.0 \mathrm{mg} / \mathrm{dl}$.
\end{abstract}

\section{Introduction}

Serum oxalate concentration increases during chronic renal failure $(1,2)$, and is above normal in virtually all patients who require chronic dialysis (3-5), because oxalate is removed from the body almost entirely by filtration at the renal glomerulus (6-8) and by secretion in the early portions of the proximal tubules (9-11). In some patients with chronic renal failure, crystals of calcium oxalate have been identified in kidney, blood vessels, myocardium, thyroid, synovia, cartilage, bone, and periodontium (12-17). The formation of crystals indicates that

This work was presented in part at the American Society of Nephrology, Washington, DC, 1984, and the American Society of Nephrology, New Orleans, 1985, and was published as abstracts (1985. Kidney Int. 27: 251 and 1986. Kidney Int. 29:315).

Received for publication 21 October 1985.

J. Clin. Invest.

(c) The American Society for Clinical Investigation, Inc.

0021-9738/86/06/1888/09 $\$ 1.00$

Volume 77, June 1986, 1888-1896 calcium oxalate concentrations in these tissues must have exceeded the solubility limit on some occasions, but the mechanism by which this occurs is not clear. Tissue calcium and oxalate concentrations could exceed the solubility limit because the serum itself is supersaturated with respect to calcium oxalate. Alternatively, the tissues may selectively accumulate calcium or oxalate, or they may produce oxalate. Heart, kidney, liver, erythrocytes, and leukocytes are all known to produce oxalate $(18,19)$, and, at least in kidney, tissue oxalate levels can exceed those of blood (20).

Hyperoxalemia could, but need not necessarily, cause serum supersaturation. Serum oxalate levels reported in patients with chronic renal failure have ranged from 22 to $200 \mu \mathrm{M} /$ liter (1$5,14,21-23$ ), and blood ionized calcium is generally $\sim 1 \mathrm{mM}$ (24). The chemical product of calcium ion and total oxalate is therefore $\sim 22-200 \times 10^{-9} \mathrm{M}^{2}$, far above the ion activity product of $2.25 \times 10^{-9} \mathrm{M}^{2}$, which has been determined for simple solutions at thermodynamic equilibrium with a solid phase of calcium oxalate monohydrate (25). However, the fraction of serum oxalate that is free, not involved in soluble complexes with sodium, potassium, calcium, and other cations, is unknown: in urine $<50 \%$ is usually free $(25,26)$. The divalent activity coefficient in solutions containing $140 \mathrm{mM}$ sodium is $\sim 0.325(25)$, so the free-ion activity product may be estimated as $(0.325)$ $\times(0.5) \times($ measured oxalate $) \times(0.325) \times(1 \mathrm{mM})$ or $\sim 1.16$ $10.6 \times 10^{-9} \mathrm{M}^{2}$. In other words, calculated estimates range from below to above the solubility limit, so the likelihood of serum supersaturation in chronic renal failure is difficult to gauge, and measurements of supersaturation are essential.

We have measured serum supersaturation with respect to calcium oxalate monohydrate using two independent methods, both of which have been used to estimate supersaturation in urine $(25,27,28)$. One method $(25)$ uses an iterative computer model of the polyelectrolyte equilibria of serum ultrafiltrates to calculate the calcium oxalate free-ion activity product, from which the solution activity of dissolved calcium oxalate complex [CaOx] is calculated. This value, divided by the known solubility of $[\mathrm{CaOx}]$ in aqueous solution $\left(6.16 \times 10^{-6} \mathrm{M}\right)(25)$, is the relative supersaturation of the serum with respect to calcium oxalate. In the other method $(27,28)$, serum ultrafiltrates are incubated with preformed crystals of calcium oxalate monohydrate for a period long enough to permit the attainment of thermodynamic equilibrium; the ratio of the calcium oxalate chemical product before to that at the end of the incubation, the concentration product ratio (CPR), ${ }^{1}$ gives a direct estimate of supersaturation. In addition, we have estimated serum supersaturation with respect to four other materials that could produce soft tissue crystal deposits: hydroxyapatite, brushite, calcium carbonate, and sodium hydrogen urate $(29,30)$.

1. Abbreviations used in this paper: $\mathrm{CPR}$, concentration product ratio; HPLC, high-performance liquid chromatography; RSR, relative saturation ratio. 


\section{Methods}

\section{Patients and normal subjects}

Activity products and relative supersaturation with respect to calcium oxalate, hydroxyapatite, brushite, calcium carbonate, and sodium hydrogen urate were calculated by using measurements made in fasting serum and serum ultrafiltrates from 11 patients with chronic renal failure receiving thrice-weekly hemodialysis for at least $1 \mathrm{yr}, 3$ patients with chronic renal insufficiency who did not require dialysis, and 4 normal subjects. No patient had primary hyperoxaluria or renal stones. In dialysis patients, blood samples were drawn from their arteriovenous fistulas immediately predialysis-prior to the administration of heparin-and at the end of $4 \mathrm{~h}$ of dialysis. Patients took their usual medications, including multivitamins containing pyridoxine and $100-200 \mathrm{mg}$ of vitamin C. In the three patients with chronic renal insufficiency and the four normal subjects, samples for $\mathrm{pH}$, carbon dioxide tension $\left(\mathrm{PCO}_{2}\right)$, and ionized calcium were obtained from arterialized venous blood (31), and antecubital venous blood was used for all other measurements. Each patient and normal subject collected a 24-h urine sample during the day prior to blood drawing. Oxalate excretion was $23 \pm 2 \mathrm{mg} / 24 \mathrm{~h}$ (mean \pm SEM) in the four normal subjects, $30 \pm 3$ in the three patients with renal insufficiency ( $P=$ NS vs. normal subjects), and $4 \pm 1$ in the six dialysis patients who produced urine $(P<0.001$ vs. both groups).

Using the same blood sampling methods, direct supersaturation measurements were made on serum ultrafiltrates from an additional seven patients receiving hemodialysis, and seven normal subjects; postdialysis measurements were precluded by the heparin given during dialysis, which slows the growth of the seed crystals (32). It was not possible to measure supersaturation and also calculate free ion products in the same blood samples, because this would have necessitated drawing excessive amounts of blood from each patient $(\sim 150 \mathrm{ml})$.

\section{Supersaturation measurements}

Calculated values. The calcium oxalate ion activity product was calculated using a computer program (25), with the measurements shown in Table I. The computer program calculates free ion concentrations using the concentrations of ligands and known stability constants for each of 62 species. Inasmuch as we actually measured ionized calcium, we were able to insert this known value in the program for each patient. Divalent ion activity coefficients were calculated from ionic strength in a conventional manner, using the Davies modification of the Debye-Huckel solution to the Poisson-Boltzmann equation (25). The program simultaneously solves for all possible binding interactions among the 13 measured substances. Oxalate and calcium ion activities were used to calculate the free-ion activity product. The free ions in solution are considered to be in an equilibrium with dissolved calcium oxalate [CaOx] governed by a stability constant $(K)$ of $2.74 \times 10^{3} \mathrm{M}^{-1}$. The value of [CaOx] in a solution at equilibrium with a solid phase of calcium oxalate, the solubility of [CaOx], is $6.16 \times 10^{-6} \mathrm{M}$ per liter (25). The calcium oxalate ion activity product of a solution at equilibrium is $2.25 \times 10^{-9} \mathrm{M}^{2}(25)$. The relative supersaturation is calculated as the ratio of $[\mathrm{CaOx}]$ in a particular solution to the solubility of [CaOx]. Similar calculations were performed for the other solid phases (Table II). Ratios of 1 connote a sample at equilibrium, above 1 , supersaturation, and below 1 undersaturation $(25,33)$.

Directly measured supersaturation. Ionized calcium was measured in whole blood, and total calcium and oxalate were measured in serum

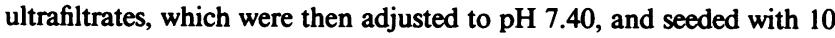
$\mathrm{mg} / \mathrm{ml}$ of preformed calcium oxalate monohydrate $(\mathrm{CaOx})$ crystals $(27$, 28, 34). After $48 \mathrm{~h}$ of incubation at $37^{\circ} \mathrm{C}$ with constant stirring, the crystals were removed by filtration through a $0.22-\mu \mathrm{m}$ Millipore filter (Millipore Corp., Bedford, MA), and total and ionized calcium and total oxalate were remeasured. The ratio of the calcium oxalate concentration product before to that after incubation, the CPR, was calculated using both the ionized and ultrafilterable calcium. Results from both calculations were similar (Table III). Calcium oxalate ion activity products were also measured in buffered solutions, containing $0.05 \mathrm{M}$ Tris- $\mathrm{HCl}$, pH 7.40, $140 \mathrm{mM} \mathrm{NaCl}$, with or without $1 \mathrm{mM} \mathrm{CaCl}_{2}$, after incubation for $48 \mathrm{~h}$ with $10 \mathrm{mg} / \mathrm{ml}$ of $\mathrm{CaOx}$ seed crystal.

\section{Chemical measurements}

Blood was drawn into sterile syringes, placed on ice, and $\mathrm{pH}, \mathrm{PCO}_{2}$, and ionized calcium were measured. An aliquot was used for measurement of serum $\mathrm{Na}, \mathrm{K}, \mathrm{Cl}, \mathrm{Ca}, \mathrm{Mg}, \mathrm{PO}_{4}$, uric acid and creatinine. The rest of the sample was then immediately centrifuged $\left(10^{\circ} \mathrm{C}\right)$ to remove cells, and ultrafiltered by centrifuging for $25 \mathrm{~min}$ at $1,700 \mathrm{~g}$ at $10^{\circ} \mathrm{C}$ in ultrafiltration cones (Centriflo 25CF, Amicon Corp., Danvers, MA).

Oxalate, citrate, and sulfate were measured in ultrafiltrates, not serum, because serum proteins affect the determination methods we used. Estimates of the degree to which blood oxalate is ultrafilterable have ranged from $86 \%$ to $95 \%(1,35)$. In dialysis patients, serum and in vivo ultrafiltrate oxalate concentrations do not differ $(128 \pm 14$ vs. $138 \pm 16 \mu \mathrm{M} /$ liter; $P=$ NS) (23). In 42 experiments, we found the ultrafiltrate to serum ratio of $\left[{ }^{14} \mathrm{C}\right]$ oxalate added to serum to be $0.98 \pm 0.02$.

Oxalate can be produced after blood has been drawn, in vitro. Oxalate may be produced nonenzymatically in serum (36); rapid ultrafiltration and precipitation, used here, minimize this source of error. Erythrocytes and leukocytes can produce oxalate through enzymatic oxidation of glyoxylate $(19,37)$, but we did not wish to add conventionally used enzyme inhibitors (37) to blood samples because of their possible interactions with oxalate, calcium, or other blood ligands. We found no increase in oxalate in a pooled serum sample from five normal volunteers, collected without inhibitors, over $30 \mathrm{~min}$ on ice; the 30 -min and starting values were both $3.6 \mu \mathrm{M} /$ liter. For patients with renal insufficiency or uremia, the issue of in vitro production in serum is less important than in normals, because the in vitro increments observed by others over periods of greater duration (36) are small (5-10 $\mu \mathrm{M} /$ liter) compared with measured values.

Oxalate. Oxalic acid was determined as the dihydroxy-quinoxaline derivative (38) using high-performance liquid chromatography (HPLC) with a C-18 reversed-phase column. After ultrafiltration, oxalate was precipitated from ultrafiltrates or buffers with saturated calcium sulfate in ethanol. The precipitate was dried and dissolved in $0.5 \mathrm{~N}$ ortho-phenylenediamine in $4 \mathrm{~N} \mathrm{HCl}$; concentrated $\mathrm{HCl}$ was added, and tubes were heated to $110^{\circ} \mathrm{C}$ for $20 \mathrm{~min}$. The resulting derivative was extracted with ethyl acetate and $8 \mathrm{M} \mathrm{NaOH}$, and the extracted compounds were dried under nitrogen. They were redissolved in distilled water and prefiltered through a $0.5-\mu \mathrm{m}$ Millex-SR filter (Millipore Corp.), before being separated and quantitated on an Altex Ultrasphere ODS reversed-phase HPLC column (Altex Scientific Inc., Berkeley, CA) $(0.46 \times 25 \mathrm{~cm})$, using a linear methanol gradient (5-30\%) in $0.35 \mathrm{M}$ ammonium acetate, monitored at $311 \mathrm{~nm}$. The dihydroxy-quinoxaline derivative eluted as a single peak at $17 \pm 1 \mathrm{~min}$ (Fig. 1). Because dicarboxylic acids and $\alpha$-keto acids form similar derivatives with ortho-phenylenediamine (39), derivatives of $\alpha$-ketoglutaric acid, fumaric acid, glyoxylic acid, phenylpyruvic acid, pyruvic acid, and succinic acid were made. None of these derivatives eluted at a retention time of $17 \pm 1 \mathrm{~min}$ under the conditions used in this analysis.

Using aqueous standards of derivatized oxalic acid, the area under the 17-min elution peak increased linearly with oxalate concentration over the range of $2.5-40 \mu \mathrm{M}$ (Fig. 2). The area of the oxalic acid peak was calculated using an integrator (model $3390 \mathrm{~A}$, Hewlett-Packard Co., Palo Alto, CA) connected to a spectrophotometer (model 100-10, Hitachi, Tokyo, Japan). Recovery of $\left[{ }^{14} \mathrm{C}\right]$ oxalate added to normal ultrafiltrates was $32 \pm 1 \%$ in 19 experiments; in eight uremic ultrafiltrates, recovery was $29 \pm 3 \%$ ( $P=\mathrm{NS}$, vs. normal). Recovery of $\left[{ }^{14} \mathrm{C}\right]$ oxalate added to standards was $25 \pm 1 \%$. Inasmuch as recoveries were very consistent, they were not measured in the uremic patients. However, in the normals, the recoveries for the CPR measurements were individually calculated because levels of oxalate are low, raising the likelihood of error; in this group, recovery was $36 \pm 1 \%$. In 12 uremic serum ultrafiltrates, oxalate was measured using both the HPLC and the zinc reduction methods (40); values were $89 \pm 4$ vs. $97 \pm 6 \mu \mathrm{M} /$ liter, for HPLC vs. zinc reduction respectively $(P=\mathrm{NS})$.

Other methods. The pH and $\mathrm{PCO}_{2}$ were measured with a blood gas analyzer (model BMS Mk III, Radiometer, Copenhagen, Denmark), and $\mathrm{HCO}_{3}$ was calculated from the Henderson-Hasselbalch equation, as described elsewhere (41). Serum and ultrafiltrate calcium and magnesium 


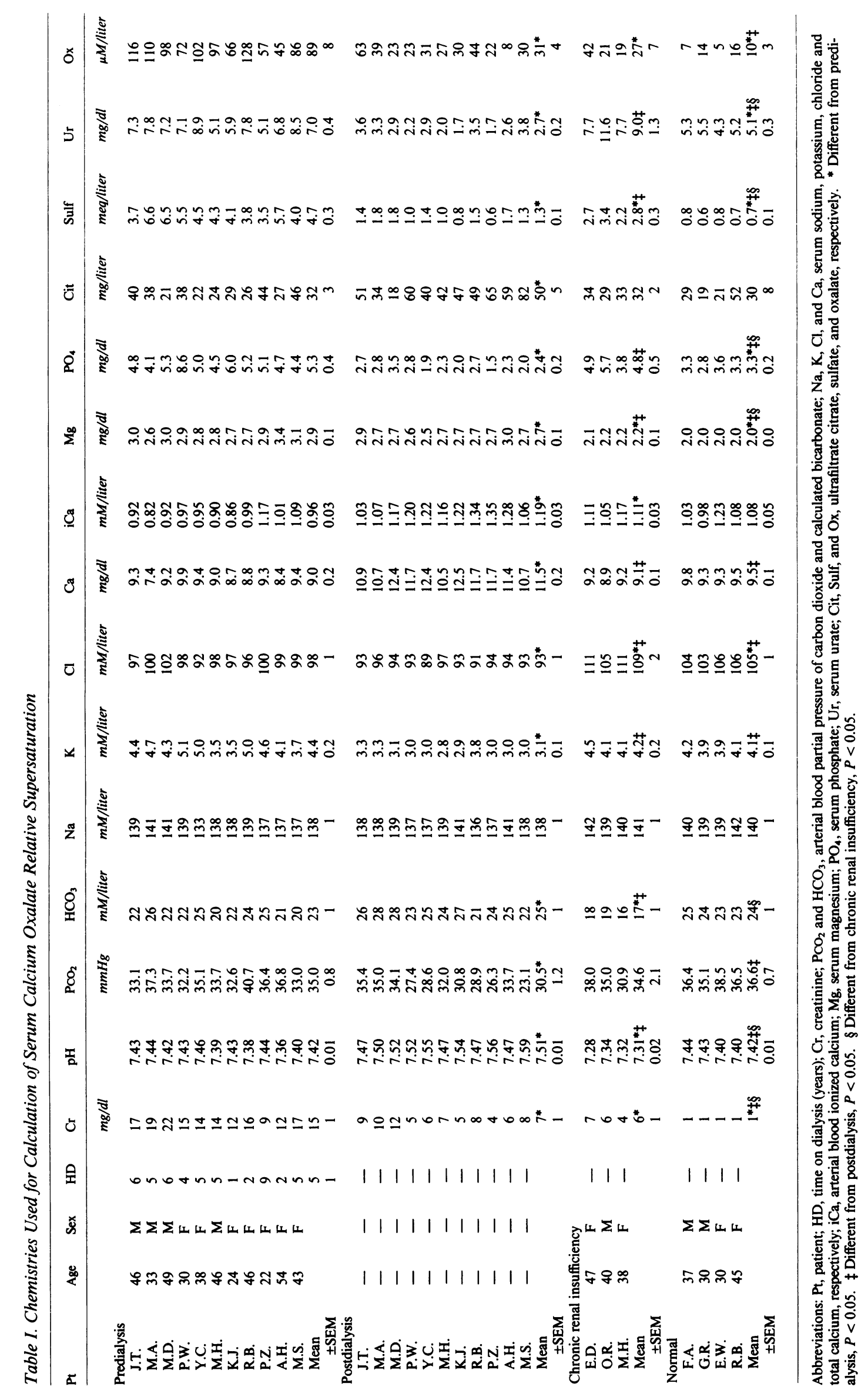




\begin{tabular}{lcccc}
\hline & Subjects & & & \\
\cline { 2 - 5 } Solid phase & Normal & CRI & Predialysis & Postdialysis \\
\hline Calcium oxalate & $0.2 \pm 0.1$ & $0.6 \pm 0.2$ & $1.7 \pm 0.1^{*} \ddagger$ & $0.7 \pm 0.1^{*} \S$ \\
Brushite & $0.25 \pm 0.02$ & $0.36 \pm 0.03^{*}$ & $0.36 \pm 0.03^{*}$ & $0.21 \pm 0.01 \ddagger \S$ \\
Hydroxyapatite $\left(\times 10^{10}\right)$ & $0.4 \pm 0.1$ & $0.5 \pm 0.2$ & $0.8 \pm 0.2$ & $0.5 \pm 0.1$ \\
Sodium hydrogen urate & $0.85 \pm 0.04$ & $1.51 \pm 0.21$ & $1.16 \pm 0.06^{*}$ & $0.46 \pm 0.04^{*} \ddagger \S$ \\
Calcium carbonate & $2.1 \pm 0.1$ & $1.3 \pm 0.1^{*}$ & $1.9 \pm 0.1 \ddagger$ & $3.2 \pm 0.1^{*} \ddagger \S$ \\
\hline
\end{tabular}

Values are means \pm SEM. Abbreviations: CRI, chronic renal insufficiency. ${ }^{*}$ Differs from normal, $P<0.05$. $\ddagger$ Differs from CRI, $P<0.05$. $\S$ Differs from predialysis, $P<0.01$.

were measured by atomic absorption spectrophotometry (Video 22, Instrumentation Laboratory Inc., Andover, MA), ionized calcium by a calcium ion-selective electrode at $37^{\circ} \mathrm{C}$ (model II, Nova, Newton, MA), sodium and potassium by flame photometry (model 443, Instrumentation Laboratory Inc.) $(28,42-44)$, phosphorus by autoanalyzer methods (Autoanalyzer model II, Technicon Instruments, Tarrytown, NY) and creatinine by autoanalyzer (relative saturation ratio [RSR]) or by the Heinegard and Tiderstrom modification of the Jaffe method (CPR) (45); the two creatinine methods gave identical results. Citrate was measured using a coupled enzyme system in the presence of NADH (Boehringer Mannheim, Indianapolis, IN), chloride by electrometric titration (BuchlerCotlove, Fort Lee, NJ), sulfate by the method of Ma and Chan (46), and urate by the uricase method (47). Urine oxalate was measured by reduction with zinc to glycolate (40).

\section{Statistical methods}

All data analysis employed conventional statistical methods for digital computer (BMDP, University of California, Los Angeles, CA). Means were compared using unpaired $t$ tests that do not assume equal variances. Stepwise regression and least square linear regression were used to analyze the relationship of total oxalate concentration to relative supersaturation and CPR. $P$ values $>0.05$ were not considered to be significant $(P=\mathrm{NS})$.

\section{Results}

Calculated supersaturation. Before dialysis, serum oxalate levels of patients exceeded normal (Table I) almost ninefold, and after dialysis by threefold. Calculated mean $( \pm$ SEM) ionic oxalate values $\left(\mathrm{M} \times 10^{-6}\right)$ were $38 \pm 3$ (predialysis) $(P<0.01$ vs. other three groups), $13 \pm 6$ (postdialysis), $12 \pm 3$ (chronic renal insufficiency) and $5 \pm 2$ (normal). The calcium $\times$ oxalate free-ion activity product (Fig. 3 ) in patients with renal failure before dialysis exceeded the solubility product $\left(P<0.01 \mathrm{vs.} K_{\mathrm{sp}}\right)$, and exceeded the ion products of the other three groups $(P<0.01$, vs. all other

Table III. Directly Measured Serum Calcium Oxalate Monohydrate Supersaturation

\begin{tabular}{|c|c|c|c|c|c|c|c|c|c|c|c|c|c|c|c|c|}
\hline \multirow[b]{2}{*}{ Patient } & \multirow[b]{2}{*}{ Age } & \multirow[b]{2}{*}{ Sex } & \multirow[b]{2}{*}{ HD } & \multirow[b]{2}{*}{ Creat } & \multicolumn{5}{|c|}{ Preincubation } & \multicolumn{5}{|c|}{ Postincubation } & \multirow[b]{2}{*}{ CPR } & \multirow[b]{2}{*}{ CPR } \\
\hline & & & & & $\mathrm{iCa}$ & UFCa & Oxalate & {$[\mathrm{iCa}](\mathrm{Ox})$} & (UFCa)(Ox) & $\mathrm{iCa}$ & UFCa & Oxalate & {$[\mathrm{iCa}](\mathrm{Ox})$} & (UFCa)(Ox) & & \\
\hline & & & & $m g / d l$ & $\begin{array}{l}m M / \\
\text { liter }\end{array}$ & $\begin{array}{l}m M / \\
\text { liter }\end{array}$ & $\begin{array}{l}\mu M / \\
\text { liter }\end{array}$ & $\times 10^{-9} \mathrm{M}^{2}$ & $\times 10^{-9} \mathrm{M}^{2}$ & $\begin{array}{l}m M / \\
\text { liter }\end{array}$ & $\begin{array}{l}m M / \\
\text { liter }\end{array}$ & $\begin{array}{l}\mu M / \\
\text { liter }\end{array}$ & $\times 10^{-9} \mathrm{M}^{2}$ & $\times 10^{-9} M^{2}$ & $\mathrm{iCa}$ & UFCa \\
\hline \multicolumn{17}{|l|}{ Uremic } \\
\hline D.A. & 41 & $\mathbf{F}$ & 7 & 13 & 1.01 & 1.35 & 107 & 108 & 145 & 0.76 & 1.11 & 91 & 69 & 101 & 1.6 & 1.4 \\
\hline E.C. & 51 & $\mathbf{F}$ & 6 & 12 & 0.97 & 1.22 & 45 & 44 & 55 & 0.69 & 1.01 & 49 & 34 & 49 & 1.3 & 1.1 \\
\hline A.A. & 24 & $\mathbf{F}$ & 4 & 18 & 0.98 & 1.28 & 88 & 86 & 113 & 0.73 & 1.06 & 87 & 64 & 92 & 1.3 & 1.2 \\
\hline S.M. & 49 & $F$ & 12 & 13 & 0.80 & 1.04 & 68 & 54 & 71 & 0.58 & 0.86 & 83 & 48 & 71 & 1.1 & 1.0 \\
\hline F.A. & 65 & $\mathbf{M}$ & 3 & 18 & 0.90 & 1.17 & 89 & 80 & 104 & 0.70 & 1.03 & 72 & 50 & 74 & 1.6 & 1.4 \\
\hline L.B. & 29 & $\mathbf{M}$ & 5 & 18 & 1.08 & 1.52 & 107 & 116 & 163 & 0.56 & - & 75 & 42 & - & 2.8 & - \\
\hline E.M. & 45 & $\mathbf{F}$ & 11 & 13 & 1.04 & 1.54 & 131 & 136 & 202 & 0.99 & 1.55 & 63 & 62 & 98 & 2.2 & 2.1 \\
\hline Mean & 43 & & 7 & 15 & 0.97 & 1.30 & 91 & 89 & 122 & $0.72^{*}$ & 1.10 & 74 & $53^{*}$ & 81 & 1.7 & 1.4 \\
\hline$\pm \mathrm{SEM}$ & 5 & & 1 & 1 & 0.04 & 0.07 & 11 & 13 & 20 & 0.05 & 0.10 & 6 & 5 & 8 & 0.2 & 0.2 \\
\hline \multicolumn{17}{|l|}{ Normal } \\
\hline J.G. & 23 & $\mathbf{M}$ & - & 1 & 1.15 & 1.31 & 5 & 6 & 7 & 0.77 & 1.24 & 25 & 19 & 31 & 0.3 & 0.2 \\
\hline J.D. & 26 & $F$ & - & 1 & 1.13 & 1.28 & 8 & 9 & 10 & 0.72 & 1.13 & 36 & 26 & 41 & 0.3 & 0.2 \\
\hline Y.N. & 45 & $\mathbf{M}$ & - & 1 & 1.02 & 1.28 & 2 & 2 & 3 & 0.92 & 1.41 & 60 & 55 & 85 & 0.04 & 0.04 \\
\hline S.P. & 23 & $\mathbf{F}$ & - & 1 & 1.16 & 1.38 & 3 & 3 & 4 & 0.86 & 1.43 & 14 & 12 & 20 & 0.3 & 0.2 \\
\hline E.B. & 31 & $\mathbf{F}$ & - & 1 & 1.00 & 1.40 & 11 & 11 & 15 & 0.92 & 1.50 & 16 & 15 & 24 & 0.7 & 0.6 \\
\hline J.C. & 32 & $\mathbf{M}$ & - & 1 & 1.18 & 1.43 & 5 & 6 & 7 & 0.51 & - & 32 & 16 & - & 0.4 & - \\
\hline W.B. & 33 & $\mathbf{M}$ & - & 1 & 1.06 & - & 24 & 25 & - & 0.61 & - & 51 & 31 & - & 0.8 & - \\
\hline Mean & 30 & & & $1 \mp$ & $1.10 \ddagger$ & 1.35 & $8 \ddagger$ & $9 \ddagger$ & $8 \ddagger$ & $0.76^{*}$ & 1.34 & $33^{*} \ddagger$ & $25^{*} \ddagger$ & $40^{*} \ddagger$ & $0.4 \ddagger$ & $0.2 \ddagger$ \\
\hline$\pm \mathrm{SEM}$ & 3 & & & & 0.03 & 0.03 & 3 & 3 & 2 & 0.06 & 0.07 & 6 & 6 & 12 & 0.1 & 0.1 \\
\hline
\end{tabular}

Abbreviations: HD, time on dialysis (years); Creat, serum creatinine; iCa, arterial blood ionized calcium; UFCa, ultrafiltrate calcium; Ox, oxalate; [iCa](Ox), product of blood ionized calcium and ultrafiltrate oxalate concentrations; (UFCa)(Ox), product of ultrafiltrate calcium and ultrafiltrate oxalate concentrations; CPR, concentration product ratio. ${ }^{*}$ Different from preincubation, $P<0.05$. $\ddagger$ Different from uremic, $P<0.05$. 
A

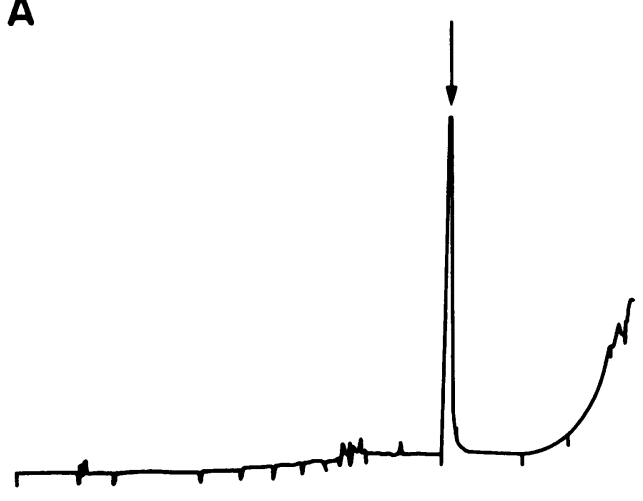

B
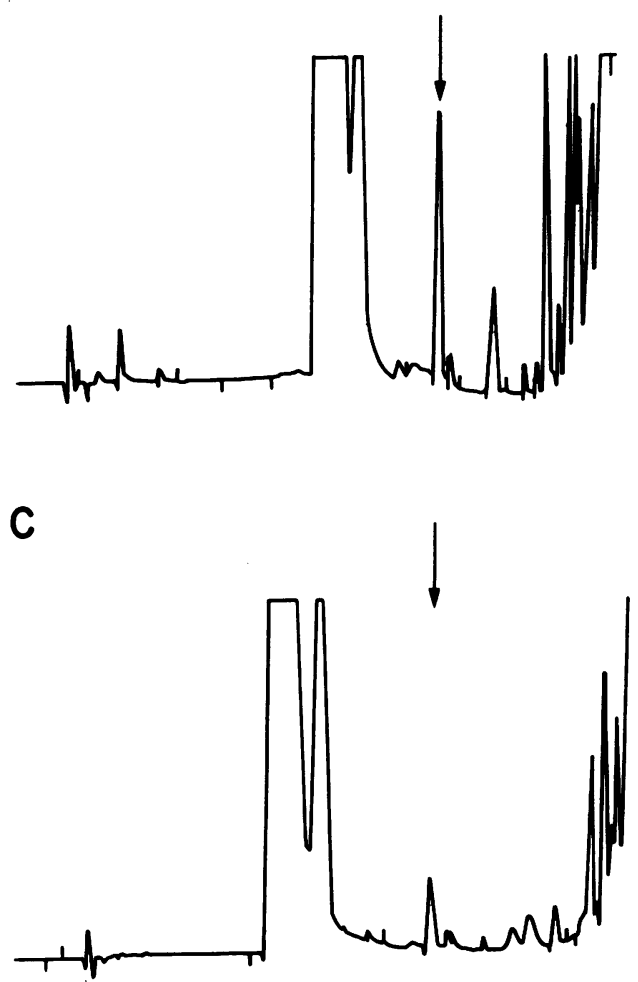

Figure 1. HPLC chromatograms of derivatized oxalate standard or serum samples. Samples were eluted from an Altex ODS Ultrasphere reversed-phase column using a linear methanol gradient (5-30\%) in ammonium acetate $0.35 \mathrm{M}$, monitored at $311 \mathrm{~nm}$. Chromatograms were plotted by a Hewlett-Packard 3390A integrator (see Methods). Elution position of derivatized oxalate indicated by arrow. $(A)$ Derivatized aqueous oxalate standard; $(B)$ derivatized serum ultrafiltrate from uremic subject; $(C)$ derivatized serum ultrafiltrate from normal subject.

groups). Although the mean ion product was below the solubility limit in the chronic renal failure patients after dialysis, and in the three patients with chronic renal insufficiency, both still exceeded that of normal subjects ( $P<0.01$, for both). The calcium oxalate relative supersaturation for the individual samples in all four groups (Fig. 4) was correlated strongly with oxalate concentration $(r=0.99, n=29, P<0.001)$. Above oxalate levels

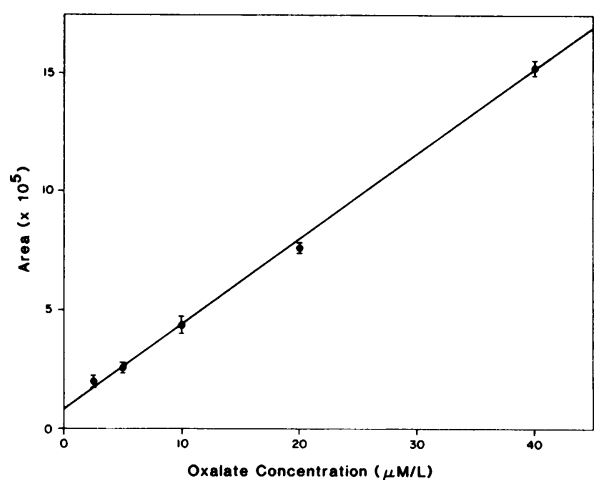

Figure 2. Calibration curve for HPLC method using aqueous oxalate standards. Standards were derivatized in the same manner as serum samples (Fig. 1), and eluted under the same conditions (see Methods). Oxalate concentration, $x$-axis; area under the elution peak at $17 \mathrm{~min}$, $y$-axis. Values are mean \pm SEM, of three to four measurements each.

of $50 \mu \mathrm{M} /$ liter, all RSR values were equal to or above 1; and all values were below 1 for oxalate levels below $40 \mu \mathrm{M}$ /liter.

All blood samples showed extreme hydroxyapatite supersaturation (Table II) and were undersaturated with respect to brushite. Calcium carbonate supersaturation in patients with uremia was subnormal before hemodialysis, but exceeded normal after dialysis. Patients with chronic renal insufficiency, and dialysis patients before hemodialysis treatments, had blood that was supersaturated with respect to sodium hydrogen urate.

Measured supersaturation. Mean CPR values were above 1 in all but one of the uremic patients (Table III), and below 1 in normal subjects; they are comparable to the calculated relative supersaturation values found in the patients and normal subjects

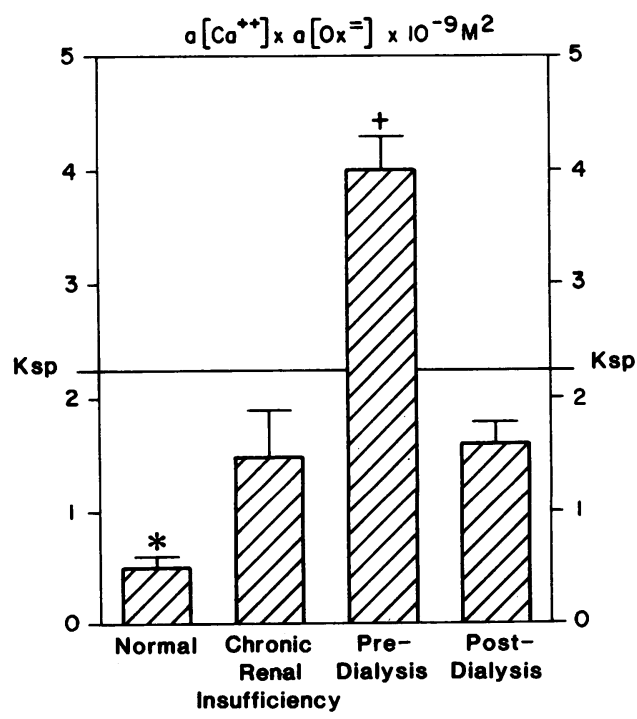

Figure 3. Calculated calcium oxalate ion activity products in serum samples from 4 normals, 3 patients with chronic renal insufficiency, and 11 uremic patients before and after dialysis (see Methods). Values are mean \pm SEM. The known thermodynamic solubility product $\left(K_{\mathrm{qp}}\right)$ of calcium oxalate at equilibrium $\left(2.25 \times 10^{-9} \mathrm{M}^{2}\right.$, see Finlayson [25]) is shown as a horizontal line. *Differs from all other groups, $P<0.01$, and less than $K_{\mathrm{ep}}, P<0.01$. +Differs from all other groups, $P<0.01$, and greater than $K_{\mathrm{sp}}, P<0.01$. 


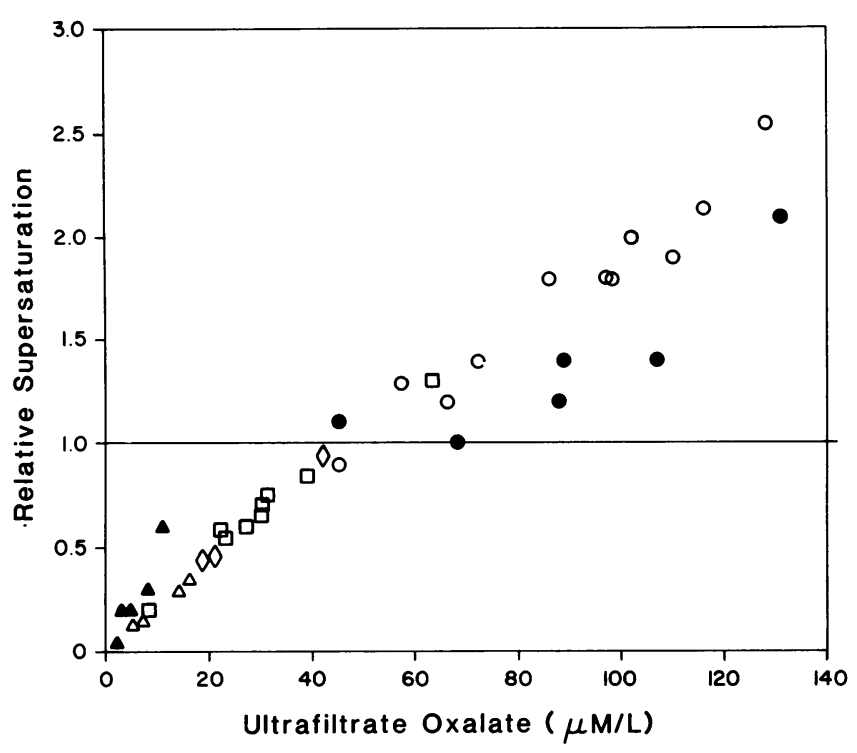

Figure 4. Relationship between supersaturation with respect to calcium oxalate ( $y$-axis) vs. ultrafiltrate oxalate concentration ( $x$-axis). Calculated relative supersaturation (RSR) in patients before $(0)$ and after ( $\square$ ) hemodialysis, in patients with predialytic chronic renal insufficiency $(\diamond)$ and in normal subjects $(\Delta)$, and CPR values, calculated with ultrafilterable calcium, for normal subjects $(\Delta)$ and uremic patients $(\bullet)$ correlated well with ultrafiltrate oxalate concentration. Two points are superimposed where oxalate $=23 \mu \mathrm{M}$ /liter and where oxalate $=44 \mu \mathrm{M}$ /liter. For both RSR and CPR, a value of 1 indicates a solution which is at equilibrium with a solid phase of calcium oxalate; values $>1$ indicate supersaturation, and $<1$ undersaturation. CPR $=1.1 \times$ ultrafiltrate oxalate $+0.14(r=0.75, n=11, P<0.001)$. $\mathrm{RSR}=1.8 \times$ ultrafiltrate oxalate $+0.11(r=0.99, n=29, P$ $<0.001)$. Regressions differed $(F=12.0, P<0.001)$.

shown in Table II. Values of CPR calculated with ultrafilterable calcium (Fig. 4) correlated with oxalate concentration $(r=0.75$, $n=11, P<0.001)$ as calculated relative supersaturation values did. However, although CPR and relative supersaturation values overlapped at some levels of serum oxalate, the regressions of relative supersaturation and of CPR on serum oxalate concentration differed; corresponding (RSR vs. CPR) slope values $(1.8 \pm 0.1$ vs. $1.1 \pm 0.3)$ and intercept values $(0.11$ vs. 0.14$)$ caused significant differences in the final regressions $(F=12.0$; $P<0.001$ ).

Simple buffered salt solutions with no initial calcium or oxalate (Methods) attained a final postincubation calcium ion $X$ chemical oxalate activity product of $3.2 \pm 0.7 \times 10^{-9} \mathrm{M}^{2}$. The final calculated ion activity product, $1.9 \pm 0.4 \times 10^{-9} \mathrm{M}^{2}$, does not differ significantly from the calcium oxalate solubility product of $2.25 \times 10^{-9} \mathrm{M}^{2}(P=\mathrm{NS})$ calculated by Finlayson (25). In six other experiments, the buffer solution initially contained $1 \mathrm{mM}$ of calcium chloride; the final ion activity product was $2.6 \pm 0.6 \times 10^{-9} \mathrm{M}^{2}$, not significantly different from $1.9 \times 10^{-9}$ $\mathrm{M}^{2}$ or $2.25 \times 10^{-9} \mathrm{M}^{2}$.

\section{Discussion}

In patients with renal failure who require dialysis, oxalate retention seems to supersaturate the blood with respect to calcium oxalate monohydrate. Calculated calcium oxalate ion activity products exceed the equilibrium product of $2.25 \times 10^{-9} \mathrm{M}^{2}$ in virtually all predialysis samples. Measured values of CPR exceed 1 , indicating supersaturation, in all predialysis samples except one. The two methods agree closely with one another, even though they have different experimental bases, and were used on different populations of patients and normals. Supersaturation correlates well enough with the ultrafiltrate oxalate concentration so that the latter is a remarkably good clinical gauge. Supersaturation of the blood means that there is a potential for nucleation and growth of calcium oxalate crystals in any perfused tissue. Because our measurements were made in ultrafiltrate, the extracellular fluid generally may be supersaturated.

Our conclusion is based upon several assumptions that were necessary for the study and seem reasonable. Our purpose was to estimate supersaturation in the aqueous phase of blood plasma. We calculated supersaturation using measurements of ionized calcium, $\mathrm{pH}$, and $\mathrm{PCO}_{2}$ in whole blood; measurements of sodium, potassium, chloride, magnesium, phosphate, and urate in serum; and measurements of citrate, sulfate, and oxalate in ultrafiltrates. We wish to extrapolate these blood, serum, and ultrafiltrate measurements to intact blood plasma. To the extent that our ultrafiltrate concentrations underestimated plasma oxalate, our estimates of supersaturation underestimate that of plasma, whereas our main conclusion is that supersaturation is common in chronic renal failure. Our direct measurements place the ultrafiltrate to plasma ratio for oxalate at $0.98 \pm 0.02$, indicating that errors from this extrapolation are minimal. Errors in citrate are unlikely to be important in our system, inasmuch as we used actual measured values of blood ionized calcium in our computer program, and these values are as close as one can get to the concentration of ionized calcium in plasma. The main effect of citrate in the program is as a ligand of calcium (25).

The CPR values are based upon different measurements. Ionized calcium was measured in blood, total calcium and oxalate in ultrafiltrates, and CPR was calculated using both ionized and total calcium values with similar results. Despite the great differences of approach, CPR and calculated supersaturation are very similar, and both vary similarly with total ultrafiltrate oxalate concentration. The concordance of the methods, and of the CPR values based on total and ionized calcium, supports the idea that our assumptions are warranted, and that we have made a reasonable measurement of supersaturation in blood. The differences between RSR and CPR are in the slope of their regressions on ultrafiltrate oxalate (Fig. 4); CPR is generally lower than RSR. This difference is reminiscent of, though not exactly comparable to, differences of these two methods applied to urine (34) and does not affect our conclusion. Because CPR and RSR depend upon calcium level only slightly, the use of ionized or ultrafiltrate calcium affects CPR only slightly and does not affect our conclusion.

Recoveries of oxalate were less than complete in our method, and we did not do $\left[{ }^{14} \mathrm{C}\right]$ oxalate recovery measurements in all of our samples; however, we view this as a reasonable approach. Our oxalate values for normals $(9 \pm 2 \mu \mathrm{M} /$ liter $)$ and uremic patients $(90 \pm 6)$ are very close to those reported by others $(22,48)$ using chemical determination methods. In addition, the zinc reduction method and HPLC method agree closely in uremic ultrafiltrates. When we measured recovery in this experiment, recovery results for normals $(36 \pm 1 \%)$ and patients $(29 \pm 3 \%)$ were not different from the mean recovery $(32 \pm 1 \%$ ) measured during the development of the method. Our seeded buffer developed equilibrium calcium $\times$ oxalate ion products indistinguishable from the published value, using our oxalate method. Measured 
CPR varies regularly with measured ultrafiltrate oxalate, whereas serious variation of the results would necessarily affect the ratio of pre- to postincubation calcium $\times$ oxalate products and increase the variability of the relationship. Finally, CPR and RSR are similar at equivalent values of ultrafiltrate oxalate, although CPR depends upon a ratio of two measurements of ultrafiltrate oxalate, and RSR upon only one oxalate measurement.

The level of supersaturation in renal failure patients prior to dialysis approximates that of normal urine $(27,28,33)$. Both the calculation and CPR approaches were, in fact, originally designed to estimate calcium oxalate supersaturation in urine $(27,33)$, and have been widely used for this purpose $(28,34)$. It is not surprising that calcium oxalate supersaturation in blood is similar to that of urine, as the blood oxalate level rises to urine levels as the kidneys fail. A major potential difference between blood and urine is that urine contains powerful inhibitors of calcium oxalate crystal growth $(49,50)$ and nucleation $(27,51)$, whereas blood may or may not. The degree of supersaturation needed to initiate crystal formation, called the formation product, is higher in urine than in simple salt solutions (27), presumably because of inhibitors. The formation product is not known for plasma, ultrafiltrates, or blood. An inhibitor, if present in blood, could increase the formation product and alter the degree of crystallization produced by a given supersaturation.

The relationship between the level of renal function and the degree of supersaturation, although very important, is not known in detail. Our studies of three patients suggest that at creatinine levels as high as $6-8 \mathrm{mg} / \mathrm{dl}$, supersaturation is not present. If this holds true for a large group of patients, then systemic calcium oxalate crystal deposition ought not to occur until patients nearly require dialysis. Local events, however, such as oxalate production (18) by kidney (52), liver (53) or heart (54), or preformed nucleation sites such as in bone (55), may foster calcium oxalate crystallization even without blood supersaturation. Likewise, the tendency of the kidney to concentrate oxalate $(20,56)$ or calcium in tubule lumens or interstitium could foster renal calcium oxalate deposits.

Because we and others have found that oxalate varies regularly with serum creatinine concentration, we can estimate the approximate level of creatinine at which oxalate will exceed 40 $50 \mu \mathrm{M} /$ liter, the threshold of supersaturation. Compilation of the available data from the literature $(1,4,5,37,57)$, and from this study, allows us to construct a reasonable regression relationship, which suggests a creatinine of $9 \mathrm{mg} / \mathrm{dl}$ as the level at which supersaturation would almost universally occur in chronic renal failure (Fig. 5), and a level of about $7 \mathrm{mg} / \mathrm{dl}$ at which supersaturation would first occur.

Blood calcium oxalate supersaturation probably is responsible for the crystals of calcium oxalate seen in kidney, myocardium, blood vessels, and other tissues (12-17) in patients with uremia. These deposits have been associated with conduction defects (16), congestive heart failure $(16,58)$, arthritis $(14)$, bone disease (55), periodontal disease (17), granulomas (59), and a vasculitis-like syndrome (15). Calcium oxalate crystals may be able to trigger inflammatory reactions through complement activation in situ (60). Oxalate crystals are certainly a factor in the renal failure and systemic disease produced by hereditary oxalate overproduction states $(61,62)$, drugs $(63)$, and toxins (64) that increase oxalate production, as well as in the hyperoxaluria seen with various intestinal diseases and after ileal resection or bypass (26); thus calcium oxalate supersaturation has an obvious potential to produce disease.

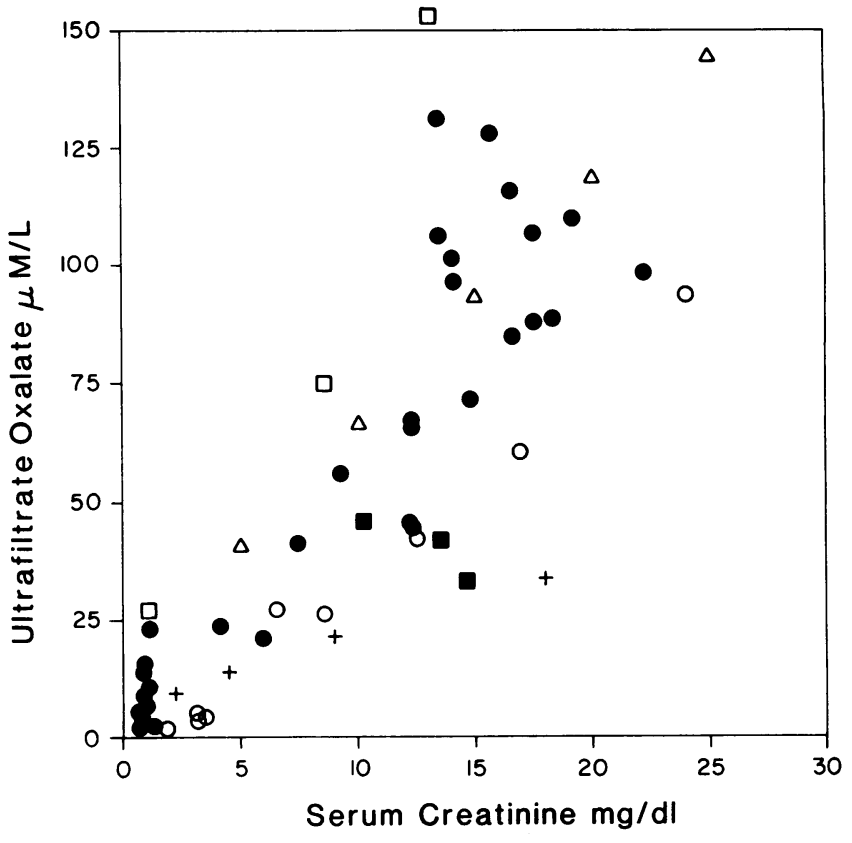

Figure 5. Serum oxalate concentration ( $y$-axis) vs. serum creatinine level ( $x$-axis). Data compiled from five reported studies: (0) Constable et al. (1); (+) Boer et al. (4); (ㅁ) Balcke et al. (5); (口) Akcay and Rose (37); ( $\Delta$ ) Barsotti et al. (57); (๑) the present study. Three points are superimposed where creatinine $=1 \mathrm{mg} / \mathrm{dl}$ and oxalate $=5 \mu \mathrm{M} /$ liter. Oxalate $=5.2 \times$ creatinine $+2.34(r=0.84, n=57, P<0.001)$. Serum oxalate seems to achieve a value of $40-50 \mu \mathrm{M}$ /liter, the lower limits of supersaturation, at serum creatinine values of $\sim 9 \mathrm{mg} / \mathrm{dl}$.

We have shown that dialysis lowers supersaturation, so one might expect well-dialyzed patients to have fewer deposits than patients whose dialysis has been delayed or inadequate. Salyer and Keren (13) found fewer deposits in patients treated by chronic hemodialysis than in those receiving peritoneal dialysis or in undialyzed patients with chronic renal failure.

Other maneuvers that lower supersaturation may also reduce deposits. Pyridoxine may lower serum oxalate levels in renal failure patients; Balcke and co-workers (65) found that serum oxalate levels decreased from 149.5 to $93.8 \mu \mathrm{M} /$ liter after $4 \mathrm{wk}$ of pyridoxine treatment. Supersaturation would decrease from 2.6 before treatment to 1.7 afterwards, if our oxalate measurement method gives comparable results with theirs, and the other serum values that control supersaturation were comparable: therefore the treatment may not abolish supersaturation. Barsotti et al. (57) found that a low protein diet supplemented with essential amino acids and keto-acid analogues lowered serum oxalate from 64.1 to $35.9 \mu \mathrm{M} /$ liter in a group of patients with chronic renal failure not on dialysis. This would lower relative supersaturation from 1.2 to 0.7 , a potentially important change.

Overall, hyperoxalemia in chronic renal failure produces supersaturation of the blood with respect to calcium oxalate monohydrate, and therefore has the potential to cause systemic soft tissue calcium oxalate deposition. The supersaturation seems to be nearly universal in patients who require dialysis, and is improved by dialysis. Supersaturation clearly does result in calcium oxalate deposition in some patients, and may play a role in the systemic disease of renal failure. Evaluation of therapies that seek to lower serum oxalate should include estimates of their effect on supersaturation. 


\section{Acknowledgments}

The expert technical assistance of Siok Le Dun is gratefully acknowledged.

This study was supported by grant AM-33949 from the National Institute of Health; Dr. Worcester was supported by National Research Service Award AM-07421.

\section{References}

1. Constable, A. R., A. M. Joekes, G. P. Kasidas, P. O'Regan, and G. A. Rose. 1979. Plasma level and renal clearance of oxalate in normal subjects and in patients with primary hyperoxaluria or chronic renal failure or both. Clin. Sci. (Lond.). 56:299-304.

2. Krouri, A., C. Jacobs, G. Charransol, and J. P. Clavel. 1980. Plasma and urinary oxalic acid in normal subjects, in patients with chronic renal failure and in patients treated by maintenance hemodialysis. Kidney Int. 18:799.

3. Zarembski, P. M., A. Hodgkinson, and F. M. Parsons. 1966. Elevation of the concentration of plasma oxalic acid in renal failure. Nature (Lond.). 212:511-512.

4. Boer, P., L. van Leersum, R. J. Hene, and E. J. Dorhout Mees. 1984. Plasma oxalate concentration in chronic renal disease. Am. J. Kidney Dis. 4:118-122.

5. Balcke, P., P. Schmidt, J. Zazgornik, H. Kopsa, and E. Deutsch. 1980. Secondary oxalosis in chronic renal insufficiency. N. Engl. J. Med. 303:944.

6. Elder, T. D., and J. B. Wyngaarden. 1960. The biosynthesis and turnover of oxalate in normal and hyperoxaluric subjects. J. Clin. Invest. 39:1337-1344.

7. Hodgkinson, A., and R. Wilkinson. 1974. Plasma oxalate concentration and renal excretion of oxalate in man. Clin. Sci. Mol. Med. 46:61-73.

8. Prenen, J. A. C., P. Boer, E. J. Dorhout Mees, H. J. Endeman, and $\mathrm{O}$. H. Yoe. 1981. Determination of oxalic acid clearance and plasma concentration by radioisotope infusion. Acta Med. Scand. 209:87-91.

9. Weinman, E. J., S. J. Frankfurt, A. Ince, and S. Sansom. 1978. Renal tubular transport of organic acids. J. Clin. Invest. 61:801-806.

10. Knight, T. F., S. C. Sansom, H. O. Senekjian, and E. J. Weinman. 1981. Oxalate secretion in the rat proximal tubule. Am. J. Physiol. 240: F295-F298.

11. Senekjian, H. O., and E. J. Weinman. 1982. Oxalate transport by proximal tubule of the rabbit kidney. Am. J. Physiol. 243:F271F275.

12. Fayemi, A. O., M. Ali, and E. V. Braun. 1979. Oxalosis in hemodialysis patients. Arch. Pathol. Lab. Med. 103:58-62.

13. Salyer, W. R., and D. Keren. 1973. Oxalosis as a complication of chronic renal failure. Kidney Int. 4:61-66.

14. Hoffman, G. S., H. R. Schumacher, H. Paul, V. Cherian, R. Reed, A. G. Ramsay, and W. A. Franck. 1982. Calcium oxalate microcrystalline-associated arthritis in end-stage renal disease. Ann. Intern. Med. 97:36-42.

15. Op de Hoek, C. T., P. P. N. M. Diderich, S. Gratama, and E. J. M. Weijs- v. Hofwegen. 1980. Oxalosis in chronic renal failure. Proc. EDTA. 17:730-735.

16. Salyer, W. R., and G. M. Hutchins. 1974. Cardiac lesions in secondary oxalosis. Arch. Intern. Med. 134:250-252.

17. Fantasia, J. E., A. S. Miller, S. Y. Chen, and W. B. Foster. 1982. Calcium oxalate deposition in the periodontium secondary to chronic renal failure. Oral Surg. 53:273-279.

18. Williams, H. E., and L. H. Smith. 1978. Primary hyperoxaluria. In The Metabolic Basis of Inherited Disease. J. B. Stanbury, J. B. Wyngaarden, and D. S. Fredrickson, editors. McGraw-Hill, New York. 182204.

19. Smith, L. H., R. L. Bauer, and H. E. Williams. 1971. Oxalate and glycolate synthesis by hemic cells. J. Lab. Clin. Med. 78:245-254.

20. Hautmann, R., A. Lehmann, and S. Komor. 1980. Intrarenal distribution of oxalic acid, calcium, sodium, and potassium in man. Eur. J. Clin. Invest. 10:173-176.

21. Ramsay, A. G., and R. G. Reed. 1984. Oxalate removal by hemodialysis in end-stage renal disease. Am. J. Kidney Dis. 4:123-127.

22. Wolthers, B. G., and M. Hayer. 1982. The determination of oxalic acid in plasma and urine by means of capillary gas chromatography. Clin. Chim. Acta. 120:87-102.

23. Balcke, P., P. Schmidt, J. Zazgornik, A. Haubenstock, and $H$. Kopsa. 1984. In vitro synthesis of oxalic acid has no relevant influence on plasma oxalic acid levels in haemodialysis patients. J. Clin. Chem. Clin. Biochem. 22:261-263.

24. Coburn, J. W., M. M. Popovtzer, S. G. Massry, and C. R. Kleeman. 1969. The physicochemical state and renal handling of divalent ions in chronic renal failure. Arch. Intern. Med. 124:302-311.

25. Finlayson, B. 1977. Calcium stones: some physical and clinical aspects. In Calcium Metabolism in Renal Failure and Nephrolithiasis. D. S. David, editor. John Wiley \& Sons, New York. 337-382.

26. Smith, L. H. 1980. Enteric hyperoxaluria and other hyperoxaluric states. In Nephrolithiasis. F. L. Coe, editor. Churchill-Livingstone, New York. 136-164.

27. Pak, C. Y. C., and K. Holt. 1976. Nucleation and growth of brushite and calcium oxalate in urine of stone formers. Metab. Clin. Exp. 25:665-673.

28. Weber, D. V., F. L. Coe, J. H. Parks, M. S. L. Dunn, and V. Tembe. 1979. Urinary saturation measurements in calcium nephrolithiasis. Ann. Intern. Med. 90:180-184.

29. McCarty, D. J. 1972. Pseudogout: articular chondrocalcinosis. In Arthritis and Allied Conditions. J. L. Hollander and D. J. McCarty, editors. Lea and Febiger, Philadelphia. 1140-1160.

30. Contiguglia, S. R., A. C. Alfrey, N. L. Miller, D. E. Runnells, and R. Z. Le Geros. 1973. Nature of soft tissue calcification in uremia. Kidney Int. 4:229-235.

31. Forster, H. V., J. A. Dempsey, J. Thomson, E. Vidruk, and G. A. DoPico. 1972. Estimation of arterial $\mathrm{PO}_{2}, \mathrm{PCO}_{2}, \mathrm{pH}$, and lactate from arterialized venous blood. J. Appl. Physiol. 32:134-137.

32. Robertson, W. G., M. Peacock, and B. E. C. Nordin. 1973. Inhibitors of the growth and aggregation of calcium oxalate crystals in vitro. Clin. Chim. Acta. 43:31-37.

33. Robertson, W. G., M. Peacock, and B. E. C. Nordin. 1968. Activity products in stone-forming and non-stone-forming urine. Clin. Sci. (Oxf.). 34:579-594.

34. Pak, C. Y. C., Y. Hayashi, B. Finlayson, and S. Chu. 1977. Estimation of the state of saturation of brushite and calcium oxalate in urine: a comparison of three methods. J. Lab. Clin. Med. 89:891-901.

35. Zarembski, P. M., and A. Hodgkinson. 1965. The fluorimetric determination of oxalic acid in blood and other biological materials. Biochem. J. 96:717-721.

36. Cole, F. E., K. M. Gladden, D. J. Bennett, and D. T. Erwin. 1984. Human plasma oxalate concentration re-examined. Clin. Chim. Acta. 139:137-143.

37. Akcay, T., and G. A. Rose. 1980 . The real and apparent plasma oxalate. Clin. Chim. Acta. 101:305-311.

38. Phillips, M. A. 1928. The formation of 2-substituted benziminazoles. J. Chem. Soc. 2393-2399.

39. Hayashi, T., H. Tsuchiya, H. Todoriki, and H. Naruse. 1982. High performance liquid chromatographic determination of $\alpha$-keto acids in human urine and plasma. Anal. Biochem. 122:173-179.

40. Hodgkinson, A., and A. Williams. 1972. An improved colorimetric procedure for urine oxalate. Clin. Chim. Acta. 36:127-132.

41. Bushinsky, D. A., N. S. Krieger, D. I. Geisser, E. B. Grossman, and F. L. Coe. 1983. Effects of $\mathrm{pH}$ on bone calcium and proton fluxes in vitro. Am. J. Physiol. 245:F204-F209.

42. Coe, F. L., J. J. Firpo, D. L. Hollandsworth, L. Segil, J. M. Canterbury, and E. Reiss. 1975. Effect of acute and chronic metabolic acidosis on serum immunoreactive parathyroid hormone in man. Kidney Int. 8: 262-273.

43. Coe, F. L., A. L. Strauss, V. Tembe, and S. L. Dun. 1980. Uric acid saturation in calcium nephrolithiasis. Kidney Int. 17:662-668. 
44. Millman, S., A. L. Strauss, J. H. Parks, and F. L. Coe. 1982. Pathogenesis and clinical course of mixed calcium oxalate and uric acid nephrolithiasis. Kidney Int. 22:366-370.

45. Heinegard, D., and G. Tiderstrom. 1973. Determination of serum creatinine by a direct colorimetric method. Clin. Chim. Acta. 43:305310.

46. Ma, R. S. W., and J. C. M. Chan. 1973. Endogenous sulphuric acid production: a method of measurement by extrapolation. Clin. Biochem. 6:82-87.

47. Liddle, L., J. E. Seegmiller, and L. Laster. 1959. The enzymatic spectrophotometric method for determination of uric acid. J. Lab. Clin. Med. 54:903-913.

48. Bennett, D. J., F. E. Cole, E. D. Frohlich, and D. T. Erwin. 1979. A radioenzymatic isotope-dilution assay for oxalate in serum or plasma. Clin. Chem. 25:1810-1813.

49. Robertson, W. G., M. Peacock, R. W. Marshall, D. H. Marshall, and B. E. C. Nordin. 1976. Saturation-inhibition index as a measure of the risk of calcium oxalate stone formation in the urinary tract. $N$. Engl. J. Med. 294:249-252.

50. Nakagawa, Y., V. Abram, F. J. Kezdy, E. T. Kaiser, and F. L. Coe. 1983. Purification and characterization of the principal inhibitor of calcium oxalate monohydrate crystal growth in human urine. J. Biol. Chem. 258:12594-12600.

51. Fleish, H., and S. Bisaz. 1962. Isolation from urine of pyrophosphate, a calcification inhibitor. Am. J. Physiol. 203:671-675.

52. Ratner, S., V. Nocito, and D. E. Green. 1944. Glycine oxidase. J. Biol. Chem. 152:119-133.

53. Crawhall, J. C., and R. W. E. Watts. 1962. The metabolism of glyoxylate by human and rat liver mitochondria. Biochem. J. 85:163171.

54. Trampetti, G., and L. Vantaggi-Cozzari. 1948. Metabolismo della glicina. Boll. Soc. Ital. Biol. Sper. 24:1100-1102.
55. Milgram, J. W., and W. R. Salyer. 1974. Secondary oxalosis of bone in chronic renal failure. J. Bone Jt. Surg. Am. Vol. 56:387-395.

56. Hautmann, R., and H. Osswald. 1983. Concentration profiles of calcium and oxalate in urine, tubular fluid and renal tissue-some theoretical considerations. J. Urol. 129:433-436.

57. Barsotti, G., C. Cristofano, E. Morelli, M. Meola, S. Lupetti, and S. Giovannetti. 1984. Serum oxalic acid in uremia: effect of a low-protein diet supplemented with essential amino acids and ketoanalogues. Nephron. 38:54-56.

58. O'Callaghan, J. W., S. M. Arbuckle, P. W. Craswell, P. P. Boyle, J. W. Searle, and W. R. Smythe. 1984. Rapid progression of oxalosisinduced cardiomyopathy despite adequate haemodialysis. Miner. Electrolyte Metab. 10:48-51.

59. Fayemi, A. O., and M. Ali. 1980. Sarcoid-like granulomas in secondary oxalosis: a case report. Mount Sinai J. Med. 47:255-257.

60. Boogaerts, M. A., D. E. Hammerschmidt, C. Roelant, R. L. Verwilghen, and H. S. Jacob. 1983. Mechanisms of vascular damage in gout and oxalosis: crystal induced, granulocyte mediated, endothelial injury. Thromb. Haemostasis. 50:576-580.

61. Hockaday, T. D. R., J. E. Clayton, E. W. Frederick, and L. H. Smith. 1964. Primary hyperoxaluria. Medicine (Baltimore). 43:315-345.

62. Moorhead, P. J., D. J. Cooper, and W. R. Timperley. 1975. Progressive peripheral neuropathy in patient with primary hyperoxaluria Br. Med. J. 2:312-313.

63. Frascino, J. A., P. Vanamee, and P. P. Rosen. 1974. Renal oxalosis and azotemia after methoxyflurane anesthesia. N. Engl. J. Med. 283: 676-679.

64. Parry, M. F., and R. Wallach. 1974. Ethylene glycol poisoning. Am. J. Med. 57:143-150.

65. Balcke, P., P. Schmidt, J. Zazgornik, H. Kopsa, and E. Deutsch. 1982. Effect of vitamin $B_{6}$ administration on elevated plasma oxalic acid levels in haemodialysed patients. Eur. J. Clin. Invest. 12:481-483. 